\title{
TO COMPARE THE EFFICACY, TOLERABILITY AND PATIENT ACCEPTABILITY OF ALLOPURINOL AND FEBUXOSTAT IN HYPERURICEMIC PATIENTS.
}

\footnotetext{
1. MBBS

Senior Lecturer HCM\&D

Hamdard University, Karachi.

2. MBBS. M.Phil. PhD.

Professor \& Head Pharmacology HCM\&D Hamdard University Karachi

3. MBBS. DMJ.

Associate Professor, Forensic Medicine

DIMC, Dow University of Health Sciences, Karachi.

4. MBBS. M. Phil

Professor, Pharmacology

DMC, Dow University of Health Sciences, Karachi.

5. MBBS, M.Phil, PhD

Head Department Pharmacology, $\mathrm{DMC}$

Dow University of Health Sciences, Karachi.

6. MBBS. M.Phil.

Associate Professor Pharmacology, DMC

Dow University of Health Sciences, Karachi.
}

Correspondence Address:

Dr. Tafazzul Hussain

Senior Lecturer HCM\&D

Hamdard University, Karachi.

tfzlhsn@hotmail.com

Article received on:

22/07/2019

Accepted for publication:

15/10/2019

\section{INTRODUCTION}

Since last 40-years there is continuous rise in the incidence of hyperuricemia population around the world. ${ }^{1}$ Recent data have shown that hyperuricemia and gout are increasing worldwide. ${ }^{2}$ The international prevalence rate of hyperuricemia is $0.3 \%$ with a $90 \%$ male predominance, while 10 to $20 \%$ of patients exhibit a family history. ${ }^{3}$

Hyperuricemia is presented with raised serum urate concentration above $6.8 \mathrm{mg} / \mathrm{dL}^{4}$ at which crystal retain, that appear in gout, considered severe damages to the joint structures and associated with poor kidney and cardiovascular outcomes. ${ }^{5}$

Uric acid has been derived from degradation of Shamaila Khalid ${ }^{6}$
Tafazzul Hussain', Mohsin Turab², Musarrat Sultana ${ }^{3}$, Fuad Shaikh4, Syed Saud Hasan ${ }^{5}$,

Objectives: To assess the improvement, safety and tolerability of Allopurino September 2018 to March 2019. Material \& Methods: The designed interventional study from the Department of Pharmacology Hamdard College of Medicine \& Dentistry, approved by BASR \& Ethical Review Board of Hamdard University Karachi. Initially 70 enrolled patients, 60-patients of sUA $>6.8 \mathrm{mg} / \mathrm{dl}$ were registered, after fulfilled the inclusion and exclusion criteria and written consent, detail history on pro forma and biochemical assessments (sUA, S. Creatinine, Alkaline Phosphate, SGPT, Cholesterol, HDL, LDL and Blood sugar were measured at day 0), repeated day 30,60 and 90, keep in case record file, on follow up visits for final analysis. Group A, (Febuxostat) results data were compared of sUA, S. Creatinine and biochemica follow up at day-90 from baseline. Conclusion: Improvement reported by mean of reduced uric Key words: $\quad$ Allopurinol, Febuxostat, Serum Creatinine, Uric Acid.

Article Citation: Hussain T, Turab M, Sultana M, Shaikh F, Hasan SS, Khalid S. To compare the efficacy, tolerability and patient acceptability of Allopurinol and Febuxostat in Hyperuricemic Patients. Professional Med J 2020; 27(4):796806. DOI: 10.29309/TPMJ/2020.27.04.3844

purines by xanthine oxidase, in the liver, intestine \& muscles from intrinsic source, ${ }^{6}$ while extrinsic sources are fatty meat, organ meat, and seafood, responsible for uric acid synthesis. ${ }^{7}$

Daily production of urate, approximately $70 \%$ is eliminated by the kidneys, and the remaining expel in the feces. However, the gastrointestinal passage of urate, to overcome the reduced excretion by the kidneys during renal failure. ${ }^{8}$

Allopurinol is a xanthine oxidase inhibitor, given orally and commonly applied drug in hyperuricemia treatment, owing to its efficacy and good tolerability. ${ }^{9}$ Twelve years after Allopurinol introduction in 1966, in this intervening period studied its origin, mechanism of action, general pharmacological properties, and therapeutic 
applications, later first Phase-I human studies were carried out, following several years of laboratory studies. ${ }^{10}$

Allopurinol, xanthine oxidase inhibitor treatment, generate hypoxanthine plus xanthine concentration generally in the domain of 0.3 to $0.4 \mathrm{mg} / \mathrm{dL}$, compared to a normal level of approximately $0.15 \mathrm{mg} / \mathrm{dl}^{11}$

Allopurinol dosing guidelines are considerably contrary and FDA approved up to $800 \mathrm{mg}$ daily in hyperuricemia with gout patient, British Society of Rheumatology guidelines recommended an ultimate dose of $900 \mathrm{mg} /$ daily. $^{12}$

At occasion Allopurinol titrated, starting from 100 to $200 \mathrm{mg} /$ day and followed by increasing the dosage steadily by $100 \mathrm{mg} /$ day at intervals of 1 week or 2-4 weeks' duration, but not exceeding Allopurinol recommended dose guidelines from, the FDA and European League against Rheumatism (EULAR). ${ }^{13}$

Currently introduce Febuxostat is a XO inhibitor and is a selective, non-purine, approved by the FDA in 2009, for prolong duration action. It efficacy in hyperuricemia and gout with potent urate lowering properties, but not for asymptomatic hyperuricemia. ${ }^{14}$

Febuxostat metabolized by microsomal enzyme system in the liver either active oxidized and inactive acylglucuronide metabolites. ${ }^{15}$ Kidney excrete more or less $50 \%$ of the administered Febuxostat and only $10 \%$ as unchanged form of drug. ${ }^{16}$

\section{MATERIAL \& METHODS}

The study was approved from the BASR and permission from Ethical Committee of Hamdard University, conducted at Medical OPD, Civil Hospital Karachi.

Diagnosed patients of either sex, ages varying from 38 to 69 years, with consent were registered after applying inclusion and exclusion criteria and serum uric acid concentration $>6.8 \mathrm{mg} / \mathrm{dL}^{17}$. Initially 70 patients from Medical OPD, interviewed and examined, all information about the patients in design pro forma. They were divided into two groups, A \& B, each having 30 patients, during the period of Six month from Sept 2018 to March 2019.

During follow up, 10 patients dropped out due to irregularity in visits and poor adherence to the study drugs. Registered 60-patients completed the study duration of 90-days. Drugs used in study: Allopurinol and Febuxostat.

Group-A, were treated by Allopurinol (Zyloric) $300 \mathrm{mg}$ once daily for 90 days.

Group-B, were treated by Febuxostat (Go-Uric) $80 \mathrm{mg}$ daily for 90 days.

Patient details, along with baseline serum uric acid. Patient's safety profile of serum creatinine, serum cholesterol, HDL, LDL, blood sugar, SGPT and serum alkaline phosphate, monitored from baseline (day-0) to completion of treatment(90days). Investigator collected all the data of schedule visits in case recording file (CRF) for final statistical analysis.

\section{RESULTS}

Patients of both groups were discussion in detail about the disease, its prognosis and directed to reported any adverse reaction, at schedule visit or inform the investigator. On follow up days, investigator keep case record to enter the data for final evaluation of study outcome.

Group-A registered thirty patients completed study duration of Allopurinol treatment for 90days, with the following baseline characteristics; male $22(73.3 \%)$ with mean age of $57.60+6.11$ years (range 45 to 68 years). Mean body weight $63.27+5.74$, and 16 (53.3\%) were smokers. Patients mean serum uric acid of $8.79+0.98(\mathrm{mg} /$ $\mathrm{dL})$, serum creatinine of $1.54+0.39(\mathrm{mg} / \mathrm{dL})$. Table-I

Group-B registered thirty patients, have baseline characteristics; 21 (70\%) male mean age $54.30+8.66$ years (range 40 years to 69 years), 13 (43.3\%) smokers with body weight mean $65.03+7.22$. Baseline serum uric acid \& creatinine 
parameters showed a mean $8.85+0.97$, \& 1.48+0.40. Table-I.

Evaluation of serum uric acid with safety profile by blood analysis of S. Creatinine S. Alkaline phosphatase, SGPT, Cholesterol, HDL, LDL and Blood sugar in both groups were carried out for the study duration of 90 -days.

Group-A \& B drugs belong to same class of xanthine oxidase inhibitors with different sources. Allopurinol, is a purine derivative, inhibits the conversion of xanthine into uric acid, and prevents the production of uric acid.

\section{Group-A}

(Allopurinol $300 \mathrm{mg} /$ daily): The changes of serum uric acid from day- 0 to day- 90 was mean $8.70 \pm 0.98$ to $6.40 \pm 0.86$, with percentage change was $27 \%$, serum creatinine mean $1.54 \pm 0.39$ to $1.42 \pm 0.30$, percentage change was $8 \%$. Table-II.

\section{Group-B}

(Treated with Febuxostat $80 \mathrm{mg} /$ daily orally for 90-days):

The change from day- 0 to day- 90 was of mean serum uric acid $8.85 \pm 0.97$ to $5.96 \pm 0.68$, percentage change was $33 \%$, statistically results are highly significant with $p$-value $>0.001$, serum creatinine mean $1.48 \pm 0.40$ to $1.45 \pm 0.31$, and percentage change was $2 \%$. Table-II.

Mean difference $\pm S D$ for change of serum uric acid in Group-A is $2.39 \pm 1.15$ with Group-B mean change in serum uric acid is $2.90 \pm 0.87$. Regarding decreasing the uric acid level, there was no significant difference between Allopurinol (alone) \& Febuxostat (alone). The results are statistically non-significant with p-value 0.061 . Mean difference $\pm S D$, for change of serum Creatinine in Group-A is 0.11 \pm 025 . \& in Group-B, is $0.03 \pm 0.15$. There was no significant difference between Allopurinol (alone) \& Febuxostat (alone) are statistically non-significant with p-value 0.144 shown in Table-III

Allopurinol hypersensitivity syndrome (AHS) is a rare but potentially serious risk for $2-8 \%$ of patients ${ }^{18}$. Adverse reactions in the study were reported 9 out of 30 patients of Group-A and 4 out of 30 patients in Group-B. Table-IV

Group-A, do not show any significant difference in the serum alkaline phosphatase, SGPT \& blood sugar values, but cholesterol have significant mean difference of $-2.90+4.10$ resulting significantly decreases with $p$-value $>0.001$ in group-A, HDL mean difference $0.20+05.87$ significantly increases and LDL mean difference $-2.53+6.97$ significantly decreases with $p$-value $<0.001$ at day-90. Table-VI \& VII.

In group-B treated patient's, blood parameters do not show any significant difference in the serum alkaline phosphatase, SGPT \& blood sugar values but have significant difference on cholesterol mean $12.43+20.76$ significantly decreases with p-value >0.001, HDL mean difference -7.50+ 2.58 significantly increases and LDL mean difference $4.63+5.05$, decreases significantly with $p$-value $<0.001$ at day-90. Group-B drugs can safely be given in hyperlipidemia, along with some beneficial effects. Table-VI \& VII.

Blood sugar concentration change in group-A form day-0 $117 \pm 14$ to $109 \pm 14$ at day-90 and in Group-B, $122 \pm 12$ to $111 \pm 13$ showed statistically highly significant $p$-value $>0.001$ but clinically within limit. Compare group A \& B for Change in Fasting Blood Sugar, mean difference \pm SD at Day-0 and Day-90 was $08.60 \pm 7.18$ to $10.73 \pm 7.09$. There was no significant difference between Allopurinol (alone) \& Febuxostat (alone). Table-VIII 


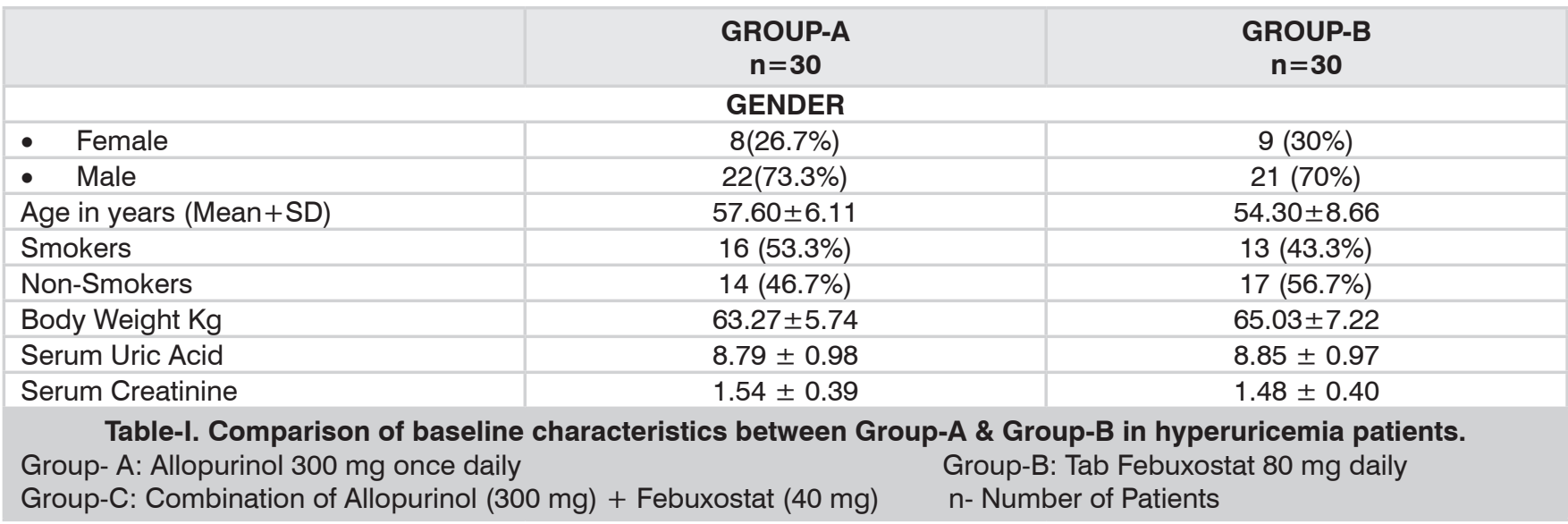

\begin{tabular}{|c|c|c|c|}
\hline Group A (Allopurinol) & Day & MEAN \pm SD & P-value* \\
\hline \multirow{3}{*}{$\begin{array}{l}\text { Serum Creatinine } \\
\mathrm{mg} / \mathrm{dl}\end{array}$} & Base line (Day - 0) & $1.54 \pm 0.39$ & \multirow{3}{*}{$0.019 * *$} \\
\hline & After treatment (Day - 90) & $1.42 \pm 0.30$ & \\
\hline & Percentage Change & $8 \%$ & \\
\hline \multicolumn{4}{|l|}{ Group B (Febuxostat) } \\
\hline \multirow[b]{2}{*}{ Serum Creatinine mg/dl } & Base line (Day - 0) & $1.48 \pm 0.40$ & \multirow[b]{2}{*}{0.258} \\
\hline & After treatment (Day - 90) & $1.45 \pm 0.31$ & \\
\hline \multirow{3}{*}{$\begin{array}{ll} & \text { Group A \& B } \\
\text { Group A } & \\
\text { Group B } & \end{array}$} & \multicolumn{2}{|c|}{ Mean Difference \pm SD } & P-value* \\
\hline & \multicolumn{2}{|c|}{$2.39 \pm 1.15$} & \multirow{2}{*}{0.061} \\
\hline & \multicolumn{2}{|c|}{$2.90 \pm 0.87$} & \\
\hline \multicolumn{4}{|c|}{ Table-III. Compare group A \& B for Change in Serum Uric Acid level (Day -0 and Day -90). } \\
\hline \multicolumn{4}{|c|}{ Compare group A \& B for Change in Serum Creatinine level } \\
\hline Group B & \multicolumn{2}{|c|}{$0.03 \pm 0.15$} & 0.144 \\
\hline$n=60$ & ndent or Paired t test & ** Significant & \\
\hline
\end{tabular}

\begin{tabular}{|c|c|c|c|c|c|}
\hline \multirow{2}{*}{ Adverse effect of drugs } & \multirow{2}{*}{ Response } & \multicolumn{2}{|c|}{ Allopurinol (alone) } & \multicolumn{2}{|c|}{ Febuxostat (alone) } \\
\hline & & No. & $\%$ & No. & $\%$ \\
\hline \multirow{2}{*}{ Palpitation } & Yes & 02 & 6.7 & 00 & 00 \\
\hline & No & 28 & 93.3 & 30 & 100 \\
\hline Headache & No & 30 & 100 & 29 & 96.7 \\
\hline \multirow{2}{*}{ Numbness } & Yes & 00 & 00 & 01 & 3.3 \\
\hline & No & 30 & 100 & 29 & 96.7 \\
\hline Abdominal pain & No & 27 & 90 & 30 & 100 \\
\hline \multirow{2}{*}{ Hematuria } & Yes & 02 & 6.7 & 01 & 3.3 \\
\hline & No & 28 & 93.3 & 29 & 96.7 \\
\hline \multirow{2}{*}{ Hypersensitivity } & Yes & 02 & 6.7 & 00 & 00 \\
\hline & No & 28 & 93.3 & 30 & 100 \\
\hline Vomiting & Yes & 00 & 00 & 01 & 3.3 \\
\hline Fatigue & No & 30 & 100 & 30 & 100 \\
\hline
\end{tabular}

Table-IV. Tolerability / safety of the drugs. (Allopurinol $300 \mathrm{mg} \&$ Febuxostat $80 \mathrm{mg}$ ). 


\begin{tabular}{|l|c|c|c|}
\hline \multicolumn{1}{|c|}{ Group A (Allopurinol) } & Day & MEAN \pm SD & P-value* \\
\hline \multirow{2}{*}{ Serum Cholesterol mg/dl } & Base line (Day - 0) & $195 \pm 30$ & $198 \pm 31$ \\
\hline Group B (Febuxostat) & After treatment (Day - 90) & & $0.001^{\star *}$ \\
\hline \multirow{2}{*}{ Serum Cholesterol mg/dl } & Base line (Day - 0) & $176 \pm 36$ \\
\cline { 2 - 4 }
\end{tabular}

Table-V. Serum Cholesterol in Group A \& B (Day -0 and Day -90).

\begin{tabular}{|l|c|c|c|}
\hline \multicolumn{1}{|c|}{ Serum HDL level in group A \& B (Day-0 and Day-90) } \\
\hline Group A (Allopurinol) & Day & MEAN \pm SD & P-value* \\
\hline \multirow{2}{*}{ Serum HDL mg/dl } & Base line (Day - 0) & $31 \pm 07$ \\
\hline Group B (Febuxostat) & After treatment (Day - 90) & $31 \pm 06$ \\
\hline Serum HDL mg/dl & Base line (Day - 0) & $29 \pm 06$ \\
\hline
\end{tabular}

\begin{tabular}{|c|c|c|c|}
\hline \multicolumn{4}{|c|}{ Serum LDL level in group A \& B (Day-0 and Day-90) } \\
\hline Group A (Allopurinol) & Day & MEAN \pm SD & P-value* \\
\hline \multirow{2}{*}{ Serum LDL mg/dl } & Base line (Day - 0) & $135 \pm 20$ & \multirow{2}{*}{0.056} \\
\hline & After treatment (Day - 90) & $137 \pm 20$ & \\
\hline \multicolumn{4}{|l|}{ Group B (Febuxostat) } \\
\hline \multirow{2}{*}{ Serum LDL mg/dl } & Base line (Day - 0) & $129 \pm 09$ & \multirow{2}{*}{$<0.001^{* *}$} \\
\hline & After treatment (Day - 90) & $124 \pm 09$ & \\
\hline \multicolumn{4}{|l|}{ * Dependent or Paired $t$ test } \\
\hline Group A \& B & \multicolumn{2}{|c|}{ Mean Difference \pm SD } & P-value* \\
\hline Group A & \multicolumn{2}{|c|}{$-2.90 \pm 4.10$} & \multirow{2}{*}{$<0.001^{\star *}$} \\
\hline Group B & \multicolumn{2}{|c|}{\begin{tabular}{|l|l|}
$12.43 \pm 20.76$ & \\
\end{tabular}} & \\
\hline \multicolumn{4}{|c|}{ Table-VI. Compare Mean Difference \pm SD in Serum Cholesterol level (Day-0 to -90$)$. } \\
\hline \multicolumn{4}{|c|}{ Compare Mean Difference \pm SD in Serum HDL level (Day-0 and Day -90$)$} \\
\hline Group A \& B & \multicolumn{2}{|c|}{\begin{tabular}{l|l} 
Mean Difference \pm SD \\
\end{tabular}} & P-value* \\
\hline Group A & \multicolumn{2}{|c|}{$0.20 \pm 05.87$} & \multirow[t]{2}{*}{$<0.001^{* *}$} \\
\hline Group B & \multicolumn{2}{|c|}{$-7.50 \pm 2.58$} & \\
\hline
\end{tabular}

\begin{tabular}{|c|c|c|}
\hline \multicolumn{3}{|c|}{ Compare Mean Difference \pm SD in Serum LDL level (Day-0 and Day -90$)$. } \\
\hline Group A \& B & Mean Difference \pm SD & P-value* \\
\hline Group A & $-2.53 \pm 6.97$ & $<0.001^{* *}$ \\
\hline Group B & $4.63 \pm 5.05$ & \\
\hline
\end{tabular}

\begin{tabular}{|c|c|c|c|}
\hline Group A (Allopurinol) & Day & MEAN \pm SD & \multirow{2}{*}{ P-value* $^{*}$} \\
\hline \multirow{2}{*}{ S. Alkaline Phosphate mg/dl } & Base line (Day-0) & $142 \pm 20$ & \multirow{2}{*}{0.156} \\
\cline { 1 - 3 } & After treatment (Day -90) & $143 \pm 20$ & \\
\hline Group B (Febuxostat) & Base line (Day - 0) & $157 \pm 13$ & \multirow{2}{*}{$0.037^{\star *}$} \\
\hline
\end{tabular}


Serum SGPT level in group A \& B (Day -0 and Day -90)

\begin{tabular}{|l|c|c|c|}
\hline Group A (Allopurinol) & Day & MEAN \pm SD & P-value* \\
\hline \multirow{2}{*}{ S. SGPT mg/dl } & Base line (Day - 0) & $30 \pm 05$ & \multirow{2}{*}{0.223} \\
\hline Group B (Febuxostat) & After treatment (Day - 90) & $31 \pm 05$ & \\
\hline \multirow{2}{*}{ S. SGPT mg/dl } & Base line (Day - 0) & $33 \pm 07$ & \multirow{2}{*}{$0.005^{\star *}$} \\
\hline
\end{tabular}

Table-VII. Serum Alkaline Phosphate in Group A \& B (Day -0 and Day -90).

\begin{tabular}{|c|c|c|}
\hline \multicolumn{2}{|c|}{ Compare Mean Difference \pm SD in Serum Alkaline Phosphate level (Day -0 and Day -90) } \\
\hline Group A \& B & Mean Difference \pm SD & P-value* $^{*}$ \\
\hline Group A & $-0.83 \pm 3.13$ & 0.961 \\
\hline Group B & $-0.80 \pm 2.0$ & \\
\hline
\end{tabular}

\begin{tabular}{|l|c|c|}
\hline \multicolumn{2}{|c|}{ Compare Mean Difference \pm SD in Serum Alkaline Phosphate level (Day $-\mathbf{0}$ and Day -90) } \\
\hline Group A \& B & Mean Difference \pm SD & P-value* $^{*}$ \\
\hline Group A & $-0.83 \pm 3.13$ & 0.961 \\
\hline Group B & $-0.80 \pm 2.0$ & \\
\hline
\end{tabular}

\begin{tabular}{|c|c|c|}
\hline \multicolumn{3}{|c|}{ Compare Mean Difference \pm SD in Serum SGPT level. (Day -0 and Day -90) } \\
\hline Group A \& B & Mean Difference \pm SD & P-value* \\
\hline Group A & $-0.76 \pm 3.37$ & \multirow{2}{*}{0.529} \\
\hline Group B & $-1.23 \pm 2.22$ & \\
\hline \multicolumn{3}{|c|}{$\begin{array}{l}\text { * Dependent or Paired t test } \\
\text { ** Significant } \\
\text { - Regarding the Alkaline Phosphate level, there was no significant difference between Allopurinol (alone) \& Febuxostat } \\
\text { (alone). } \\
\text { - Regarding the SGPT, there was no significant difference between Allopurinol (alone) \& Febuxostat (alone). }\end{array}$} \\
\hline
\end{tabular}

\begin{tabular}{|c|c|c|c|}
\hline Group A (Allopurinol) & Day & MEAN \pm SD & P-value* \\
\hline \multirow{2}{*}{$\begin{array}{l}\text { Fasting Blood Sugar } \\
\text { mg/dl }\end{array}$} & Base line (Day - 0) & $117 \pm 14$ & \multirow{2}{*}{$<0.001^{* *}$} \\
\hline & After treatment (Day -90$)$ & $109 \pm 14$ & \\
\hline \multicolumn{4}{|l|}{ Group B (Febuxostat) } \\
\hline \multirow{2}{*}{$\begin{array}{l}\text { Fasting Blood Sugar } \\
\mathrm{mg} / \mathrm{dl}\end{array}$} & Base line (Day - 0) & $122 \pm 12$ & \multirow{2}{*}{$<0.001^{* *}$} \\
\hline & After treatment (Day - 90) & $111 \pm 13$ & \\
\hline
\end{tabular}

\begin{tabular}{|c|c|c|}
\hline Group A \& B & Mean Difference \pm SD & P-value* $^{*}$ \\
\hline Group A & $08.60 \pm 7.18$ & 0.252 \\
\hline Group B & $10.73 \pm 7.09$ & \\
\hline
\end{tabular}

Compare group A \& B for Change in Fasting Blood Sugar level. (Day -0 and Day -90). 


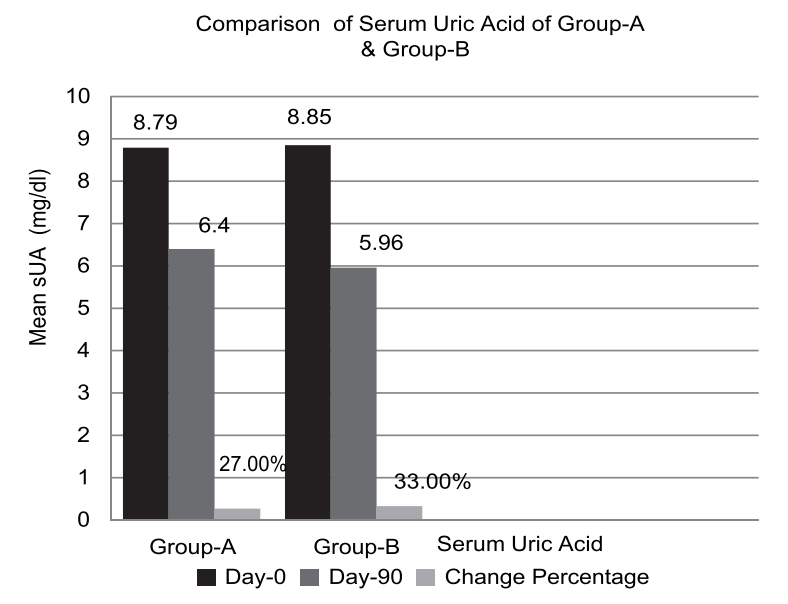

Figure-1

Comparison of Serum Creatinine of Group-A \& Group-B

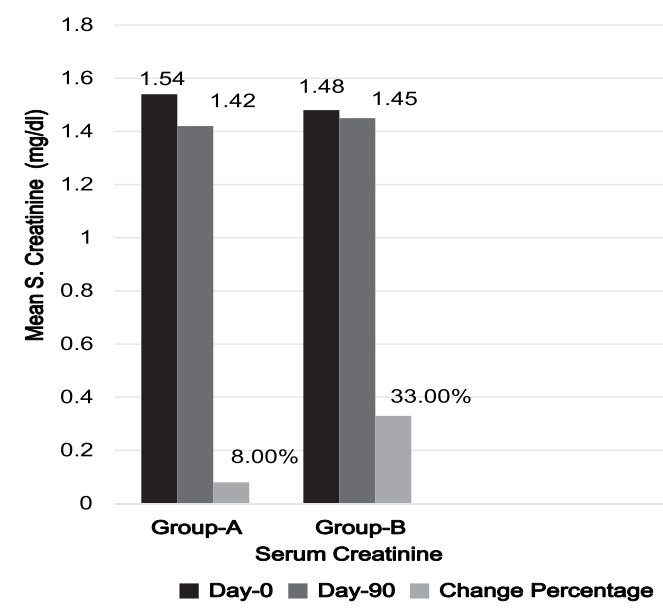

Figure-2

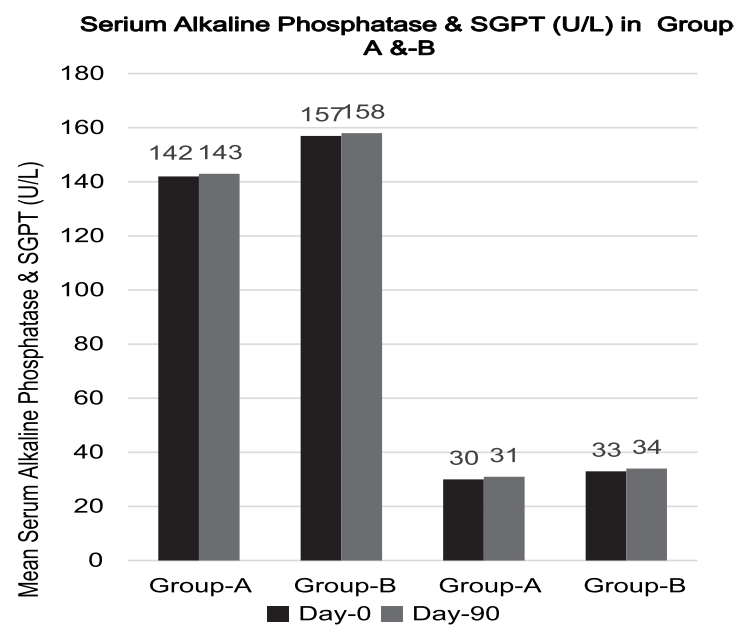

Figure-3 Comparison of Blood parameters of Liver Functions Comparison of serum Alkaline Phosphate \& SGPT. Group-A \& Group-B
Comparison of Serum Cholestrol,HDL, LDL in Group-A \& B

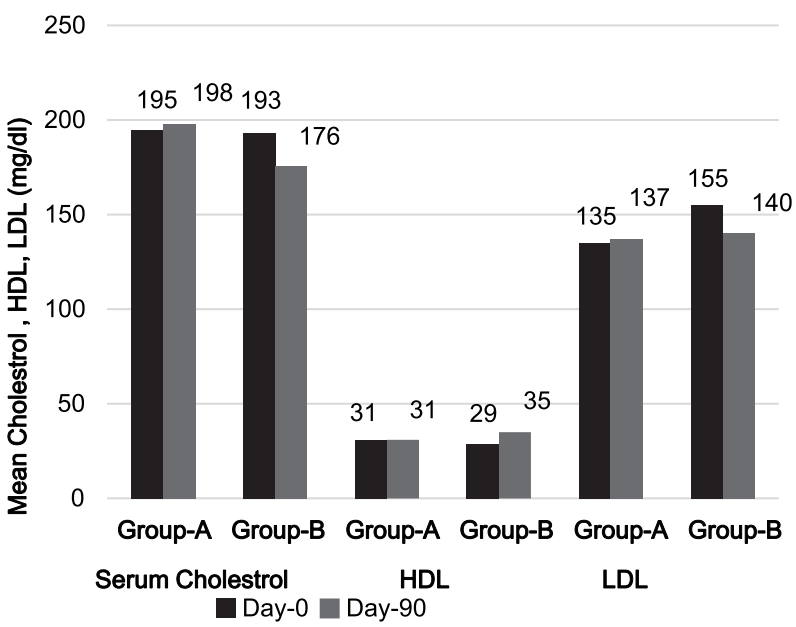

Figure-4. Comparison of Serum Cholesterol, HDL, LDL in Group-A \& B.

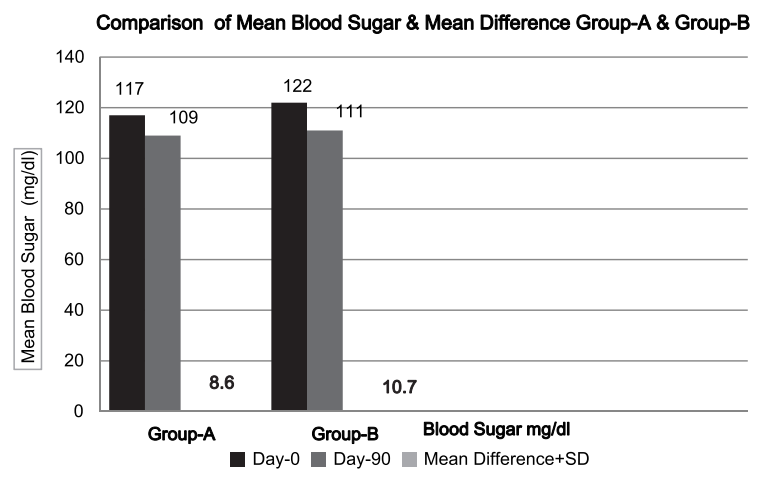

Figure-5: Comparison of Mean Blood Sugar \& Mean Difference + SD Group-A \& Group-B.

\section{DISCUSSION}

Hyperuricemia prevalence not only reported in developed countries but evidence come up in the low and middle-income countries, that incidences are also ascending. ${ }^{19}$

The prevalence of hyperuricemia is $1-4 \%$. In European countries, male predominance $3-6 \%$ than female $1-2 \%$, as the age advances prevalence rises $10 \% \& 6 \%$ respectively in both sex. Yearly incidence is 2.68 per 1000 persons, in male $2-6$ folds more than female. ${ }^{20}$

Hyperuricemia pathophysiology is not clearly known, imbalance of breakdown of purines and uric acid excretion is answerable to its action. Most cases of hyperuricemia clinically reported 
because of faulty urate excretion. Elevated SUA is now established as a potential risk factor for developing number of diseases like, insulin resistance, increased blood pressure, lipid disturbances and cardiovascular diseases. ${ }^{21}$

Hyperuricemia in the initial days recognized as gout, but now consider a separate entity and responsible for numbers of metabolic and hemodynamic abnormalities. ${ }^{22}$

In our study, the aim of therapy is to treat hyperuricemia with the minimum therapeutic dose and hence minimize the risk of adverse effects, efforts to suppress serum uric acid over long term and prevent relapse. The allopurinol a standard treatment in hyperuricemia since long compare with newly FDA approved drug Febuxostat, in addition to assess the tolerability/safety.

The present study findings with Allopurinol treatment, the serum uric acid reduced from $8.79+0.98$ day- 0 to $6.40+0.86$ on day 90 , total percentage change was $27 \%$. Statistically highly significant $<0.001$ and findings are in agreement with the study conducted by Becker, 2005. ${ }^{11}$

In renal dysfunctions, better option to start with the minimum dose, a reduced initial target dosage in renal impairment is still defend, but studies support that when unable to obtained desire effects, the dosage may be increased above the present guidelines. In our study, the renal function assessment are within normal limit and allopurinol therapy does not influenced the serum Creatinine level, results agree with (Day, 2007). ${ }^{23}$

Our study does not agree with (Wei Li, 2005), ${ }^{24}$ in which a significant limitation of allopurinol therapy in reducing the serum uric acid, in less than $50 \%$ of patients receiving standard dose of $300 \mathrm{mg}$ daily.

Study conducted by (Perez $\square$ Ruiz, 2000) ${ }^{25}$ validated, that higher doses of allopurinol are more effective in decreasing concentration of uric acid, but Allopurinol $300 \mathrm{mg}$ in recommended dosage are similarly adequate in decreasing uric acid concentration without influencing the renal functions, results matched with our study.

Our results agree with (Gerald 1975), ${ }^{26}$ study, with single $300-\mathrm{mg}$ of Allopurinol per day appears to be beneficial in individuals with hyperuricemia.

Febuxostat, non-purine potent xanthine oxidative inhibitor, used as an alternative to allopurinol Grassi, 2014 ${ }^{27}$ established logical and wellestablished outcomes, for short period of 1 to 6 months duration use of Febuxostat significantly reduces the serum uric acid concentrations. Our study of 90-day treatment with Febuxostat, supported the study.

Becker, 2005, ${ }^{11}$ clinical trial of 52 weeks duration, in which SUA was reduced to $6.0 \mathrm{mg} / \mathrm{dL}$, during 3-month study, Febuxostat with Allopurinol, matched with our results in the reduction of serum uric acid at day 90 in the duration of therapy, results more marked with Febuxostat than Allopurinol.

Our study also agrees with (Borghi, 2016) ${ }^{28}$ reported, that in hyperuricemia, Febuxostat is a suitable option and considered as first line drug, provided safe and efficient in number of clinical studies.

A study of $28 \square$ weeks by Schumacher, ${ }^{29}$ conducted in 2008, of different doses, Febuxostat more adequately reduces and maintained serum urate levels $<6.0 \mathrm{mg} / \mathrm{dl}$ than allopurinol, at doses (300 or $100 \mathrm{mg}$ ) or placebo in hyperuricemic patients and gout, with mild to moderately renal dysfunction. In our study, does of $300 \mathrm{mg}$ of Allopurinol \& Febuxostat of $80 \mathrm{mg}$ productively decreased SUA, without any disturbances of renal function and better effects reported with Febuxostat group of patients.

In our study Febuxostat $80 \mathrm{mg}$, daily dose were more effectively reduces the sUA concentration $39 \%$ than allopurinol at daily dose of $300 \mathrm{mg}$ in which showed $27 \%$ reduction of sUA, results agrees with Michael, ${ }^{30}$ clinical study in 2005, in hyperuricemia and gout patients. Prompt and persistent reduction in SUA, less than $6.0 \mathrm{mg} / \mathrm{dL}$ more marked in patients treated with daily $80 \mathrm{mg}$ 
Febuxostat than $300 \mathrm{mg}$.

Becker $2005^{11}$ controlled trial of Febuxostat versus Allopurinol of 52 week randomized, randomized 760 patients to 1 of 3 study groups of Febuxostat $80 \mathrm{mg}$, Febuxostat $120 \mathrm{mg}$ and allopurinol 300 $\mathrm{mg} /$ day and compared the safety and efficacy. During the study measured SUA, laboratory tests, assessed renal function, at each of the last 3 monthly visits. Our study of Febuxostat 80 $\mathrm{mg} \&$ Allopurinol $300 \mathrm{mg}$ daily for 90-days, the reduction of serum uric acid achieved the desired results.

In a study conducted in 2011 by Kamatani ${ }^{31}$ of comparative study of Allopurinol \& Febuxostat in doses $200 \mathrm{mg} \mathrm{\&} 40 \mathrm{mg} / \mathrm{d}$ respectively for the period of 44 days showed Febuxostat at $40 \mathrm{mg} /$ daily demonstrated more potent hypouricemic effects than allopurinol at $200 \mathrm{mg} / \mathrm{d}$, in our study Febuxostat $80 \mathrm{mg} / \mathrm{d}$ \& Allopurinol $300 \mathrm{mg} / \mathrm{d}$ for 90 days demonstrated that Febuxostat is more potent than allopurinol in hyperuricemia.

In another trial, (CONFIRMS trial) conducted in 2010 by Becker, ${ }^{32}$ our study showed similar efficacy in a 6-month study of 2269 patients of serum urate levels $\geq 8.0 \mathrm{mg} / \mathrm{dL}$ and compared Febuxostat proved significant reduction of uric acid levels in patients with normal renal function. Frampton $^{33}$ pointed that earlier studies have identified cardiovascular toxicities with Febuxostat, ongoing trials are in progress to identify the cardiovascular safety of Febuxostat versus allopurinol. In our study of ninety hyperuricemia patients for 90-days therapy monitoring drug safety, no adverse events except palpitation selfcontrol, reported in $4 \%$ of patients.

Laboratory data of liver function assay (Alkaline Phosphate \& SGOT) Table-VII \& Figure-3 and blood sugar results in both groups were insignificant Table-VIII \& Figure-5.

Study showed decreasing Cholesterol \& LDL but showed increased HDL values, beneficial in hyperlipidemia. Table-V \& Figure-4.

We observed no serious adverse events, related to drugs used during the study period.
There was no significant difference between Allopurinol (alone) \& Febuxostat (alone).

- Group-A: Allopurinol treated $300 \mathrm{mg} / \mathrm{d}$

- Group:-B Febuxostat treated 80mg/d

- sUA: Serum Uric Acid

- Day-0: Baseline mean value

- Day-90: Completion of study mean value

- Mg/dl: Milligram per Deciliter

- Group-A: Allopurinol treated $300 \mathrm{mg} / \mathrm{d}$

- Group:-B Febuxostat treated 80mg/d

- Day-0: Baseline mean value

- Day-90: Completion of study mean value

- Mg/dl: Milligram per Decilitre

Group-A: Allopurinol (300 mg) treated Patients Group-B: Febuxostat $(80 \mathrm{mg})$ treated Patients $\mathrm{n}$ : Total number of Patients

Group-A: Allopurinol (300 mg) treated Patients Group-B: Febuxostat $(80 \mathrm{mg})$ treated Patients $\mathrm{n}$ : Total number of Patients

Group-A: Allopurinol (300 mg) treated Patients Group-B: Febuxostat $(80 \mathrm{mg})$ treated Patients $\mathrm{n}$ : Total number of Patients

\section{CONCLUSIONS}

This clinical study, conducted in patients with hyperuricemia, and treatment with Febuxostat, Allopurinol with regard to safety and uratelowering efficacy. Administration of Febuxostat $80 \mathrm{mg}$, Allopurinol 300mg for 90-days resulted in prompt and persistent reduction in serum urate concentration.

In this study, the overall incidences of treatmentrelated adverse events were similar for all treatment groups, and were mild in severity.

For many years, allopurinol were used for lowering serum urate in patients, which reduced uric acid production through competitive inhibition of xanthine oxidase. There was moderate-quality evidence of little or no difference in the proportion of participants achieving target serum urate when allopurinol was compared with Febuxostat. However, Febuxostat seemed more successful than allopurinol in achieving a target serum urate level (6 mg/dL or less).

Copyright $\odot 15$ Oct, 2019. 


\section{REFRENCES}

1. Edwards, NL. Treatment-failure gout: a moving target. Arthritis Rheum 2008; 58:2587-2590.

2. Smith EU, Diaz-Torne C, Perez-Ruiz F, March LM. Epidemiology of gout: an update. Best Pract Res Clin Rheumatol. 2010; 24:811-27.

3. Kelley, WN \& Schumacher Jr. HR (1993). Crystalassociated synovitis. In: Kelley WN, ed. Textbook of rheumatology. 4th ed. Philadelphia: Saunders, pp. 1291-336.

4. Stamp L, Dalbeth N. Urate-lowering therapy for asymptomatic hyperuricemia: a need for caution. Semin Arthritis Rheum. 2017; 46:457-64.

5. Richette P, Perez-Ruiz F, Doherty M, Jansen TL, Nuki G, Pascual E, et al. Improving Cardio-vascular and renal outcomes in gout: what should we target? Nat Rev Rheumatol. 2014; Vol (10): 654-661.

6. Hediger MA, Johnson RJ, Miyazaki $H$, Endou $H$. Molecular physiology of urate transport. Physiology 2005; 20:125-33.

7. Kang DH, Chen W. Uric acid and chronic kidney disease: new understanding of an old problem. Semin Nephrol. 2011; 31(5):447-52.

8. Jin $M$, Yang $F$, et al. Uric acid, hyperuricemia and vascular diseases, Front Biosci. 2012; 17: 656-669.

9. Hepburn AL. Fenfibrate: A new treatment for hyperuricemia and gout. Ann Rheum Dis 2001; 60: 984-992.

10. Aung T, Myung G, FitzGerald JD. Treatment approaches and adherence to urate-lowering therapy for patients with gout. Patient Prefer Adherence 2017; 11:795-800.

11. Becker MA, Schumacher HR Jr, Wortmann RL, et al. Febuxostat compared with allopurinol in patients with hyperuricemia and gout, N Engl J Med. 2005; vol. 353: 2450-61.

12. Jordan KM, Cameron JS, Snaith M, et al. British Society for Rheumatology and British Health Professionals in Rheumatology guideline for the management of gout. Rheumatology (Oxford) 2007; 46:1372-1374.

13. Zhang W, Doherty $M$, Bardin $T$, et al. EULAR evidence based recommendations for gout. Part II: management. Report of a task force of the EULAR Standing Committee, for International Clinical Studies Including Therapeutics (ESCISIT). Ann Rheum Dis 2006; 65:1312-1324.
14. Richette P, Doherty M, Pascual E, Barskova V, Becce F, Castaneda-Sanabria J. et al. 2016 an updated EULAR evidence-based recommendations for the management of gout. Ann Rheum Dis. 2017; 76:29-42.

15. Takano $\mathrm{Y}$, Hase-Aoki K, Horiuchi H, et al. Selectivity of Febuxostat, a novel non-purine inhibitor of xanthine oxidase/xanthine dehydrogenase. Life Sci. 2005; 76:1835-1847.

16. Becker MA, Kisicki J, Khosravan R, et al. Febuxostat (TMX-67), a novel, non-purine, selective inhibitor of xanthine oxidase, is safe and decreases serum urate in healthy volunteers. Nucleosides Nucleotides Nucleic Acids 2004; 23:1111-6.

17. Wortmann RL. Chapter 87. Gout and hyperuricemia. In Firestein, GS, Budd, RC, Harris, ED Jr et al, eds. Kelley's Textbook of Rheumatology. 8th ed. Philadelphia, Pa: Aunders/Elsevier; 2009.

18. Shahid $H$, Singh JA. Investigational drugs for hyperuricemia. Expert Opin Invest Drugs. 2015; 24:1013-30.

19. Kanwar $G$ and Kabra, R. Serum uric acid level and obesity: An association. International Journal of healthcare Sciences. 2016; 4(1):52-55.

20. Kuo CF, Grainge MJ, Zhang W, Doherty M. Global epidemiology of gout: prevalence, incidence and risk factors. Nat Rev Rheumatol 2015; 11(11):649-62.

21. Ling Qiu, Xin-qi, Cheng Jie Wu, Jun-ting Liu, et al. Prevalence of hyperuricemia and its related risk factors in healthy adults from Northern and Northeastern Chinese provinces. BMC Public Health. 2013; 13: 664.

22. Stack A, Manolis AJ, Ritz E. Detrimental role of hyperuricemia on the cardio-Reno vascular system. Curr Med Res Opin. 2015 (Sep); 31 (Suppl 2):21-6.

23. Day RO, Graham GG, Hicks M, McLachlan AJ, Stocker $\mathrm{SL}$, Williams KM. Clinical pharmacokinetics and pharmacodynamics of allopurinol and oxypurinol. Clin Pharmacokinet. 2007; 46:623-644

24. Wei L, Mackenzie IS, Chen Y, Struthers AD, MacDonald TM. Impact of allopurinol use on urate concentration and cardiovascular outcome. $\mathrm{Br} \mathrm{J}$ Clin Pharmacol. $2011 ; 71: 600-7$.

25. Perez $\square$ Ruiz F, Alonso $\square R$ Ruiz A, Calabozo M, Herrero[ Beites A, Erauskin G, Ruiz $\square$ Lucea E. Efficacy of allopurinol and benzbromarone for the control of hyperuricaemia: a pathogenic approach to the treatment of primary chronic gout. Ann Rheum Dis 1998; 57: 545-9. 
26. Gerald P, Rodnan, James A. Robin, Sanford F, Tolchin. Allopurinol and Gouty Hyperuricemia Efficacy of a Single Daily Dose. JAMA. 1975; 231 (11):1143-1147.

27. Grassi D, Pontremoli R, Bocale R, Ferri C and Desideri G: Therapeutic approaches to chronic hyperuricemia and gout. High Blood Press Cardiovasc Prev. 2014. $21: 243-250$.

28. Borghi C, Perez-Ruiz F. Urate lowering therapies in the treatment of gout: a systematic review and meta-analysis. Eur Rev Med Pharmacol Sci. 2016 Mar; 20(5):983-92.

29. Schumacher HR Jr, Becker MA, Wortmann RL, et al. Effects of Febuxostat versus allopurinol and placebo in reducing serum urate in subjects with hyperuricemia and gout: a 28-week, phase III, randomized, double-blind, parallel-group trial. Arthritis Rheum. 2008; vol. 59: 1540-8.
30. Michael A. Becker H. Ralph Schumacher Jr, Robert L. Wortmann, Patricia A. et al Febuxostat Compared with Allopurinol in Patients with Hyperuricemia and Gout. Engl J Med 2005; 353:2450-2461

31. Kamatani N, Fujimori N, Hada T, et al. An AllopurinolControlled, Randomized, Double-Dummy, DoubleBlind, Parallel Between-Group, Comparative Study of Febuxostat (TMX-67), a Non-Purine-Selective Inhibitor of Xanthine Oxidase, in Patients with Hyperuricemia Including Those with Gout in Japan: Phase 3 Clinical Study Journal of Clinical Rheumatology. 2011 (JUN); 17(4): S13-S18.

32. Becker MA, Schumacher HR, Espinoza LR, Wells AF, MacDonald P, Lloyd E, Lademacher C. The uratelowering efficacy and safety of Febuxostat in the treatment of the hyperuricemia of gout: The confirms trial. Arthritis Res Ther. 2010; 12 (2):R63

33. Frampton, JE. Febuxostat: a review of its use in the treatment of hyperuricemia in patients with gout. Drugs. 2015 Mar; 75 (4):427-38.

\begin{tabular}{|c|l|l|l|}
\hline \multicolumn{3}{|c}{ AUTHORSHIP AND CONTRIBUTION DECLARATION } \\
\hline Sr. \# & \multicolumn{1}{|c|}{ Author(s) Full Name } & Contribution to the paper & Author(s) Signature \\
\hline 1 & Tafazzul Hussain & 1st Author \\
\hline 2 & Mohsin Turab & 2nd Author \\
\hline 3 & Musarrat Sultana & 3rd Author \\
\hline 5 & Syad Shaikh & 4th Author \\
\hline 6 & Shamaila Khalid & 6th Author \\
\hline
\end{tabular}

